\title{
Annual traffic noise levels estimation based on temporal stratification
}

\author{
G. Quintero*, A. Balastegui, J. Romeu
}

Laboratory of Acoustics and Mechanical Engineering (LEAM), Polytechnic University of

Catalonia, Colom 11, 08222 Terrassa, Spain

\section{Graphical abstract}

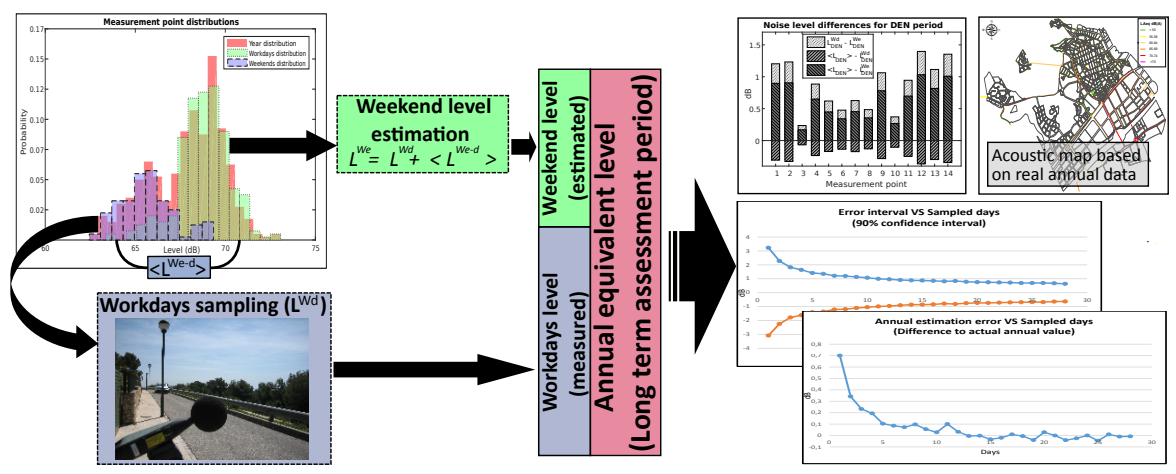

\section{Highlights}

- Improvement in the estimation of long term noise levels.

- Two statistically different strata were found partitioning weekends and workdays.

- Lower variability and higher noise levels on weekdays.

- Reduction up to $38 \%$ of the required measurement days to equal random sampling accuracy.

\footnotetext{
${ }^{*}$ Corresponding author.

E-mail address: guillermo.quintero@upc.edu
} 


\section{UPCommons}

\section{Portal del coneixement obert de la UPC}

http://upcommons.upc.edu/e-prints

(c) 2017. Aquesta versió està disponible sota la llicència CC-BY-NC-ND 4.0 http://creativecommons.org/licenses/by-nc-nd/4.0/

(c) 2017. This version is made available under the CC-BY-NC-ND 4.0 license http://creativecommons.org/licenses/by-nc-nd/4.0/ 
- Night period stratification affected by leisure activities.

\section{Abstract}

This paper proposes a temporal sampling strategy that increases the accuracy of long-term noise level estimation and allows to establish the estimation error according to the number of sampled days. Days of the week are stratified into working days and weekend days. This research shows how to use measurements of $L_{e q}$ on working days to estimate the corresponding values for weekend days. This is possible because working days have higher noise levels and less variability than weekend days. The improvement in accuracy allows for a reduction in the number of required sampled days compared to taking samples randomly, which would help to reduce the uncertainty in environmental noise assessment. As a reference, to obtain a $90 \%$ confidence interval of $\pm 1 \mathrm{~dB}$ for $L_{\text {day }}$, the proposed sampling strategy reduces the required measurement days by more than $38 \%$. For $L_{D E N}$, the reduction is close to $18 \%$ of the total number of days. The proposed strategy could be adapted to different environments by simply changing a few parameters. Keywords: Temporal variability, Sampling strategy, Noise assessment, Noise mapping

\section{Introduction}

Noise pollution is one of the main environmental issues in cities as it leads to health problems for inhabitants. The exposure to high noise levels can affect sleep, lead to cardiovascular diseases, cause cognitive problems and

5 even cause property prices to fall [1-5]. It is therefore essential to accurately assess the noise levels to which the population is exposed in order to draw 
up and evaluate the effect of environmental noise management strategies [6]. The main basic tool for this purpose are noise maps. According to European Directive 2002/49/EC [7], for strategic noise mapping, the minimum time recommended for noise assessment is one year and should be done (at least) for the indicators $L_{D E N}$ and $L_{\text {night }}$. Such maps are available for many agglomerations in Europe but in most cases the information is incomplete due to the lack of data [8]. Models and standards are also applied inconsistently [9] and the accuracy of the given results is unknown.

Although numerical noise models are the preferred tool for noise mapping, $[10,11]$, undertaking noise measurements is an essential task for: calibrating noise map modelling tools $[12,13]$, evaluating the effect of local noise reduction strategies such as green zones [14-16], obtaining results in complex environments where the traffic is not the main noise source [17] or traffic data is not available [13], and obtaining more accurate results [18]. The use of experimental noise measurements is a highly demanding task that is usually simplified using sampling strategies that, as a drawback, could lead to significant differences between the estimated and the actual annual values.

A good approach to reduce variability is to take into account the spatial and temporal correlation $[19,20]$. In terms of the temporal aspect of noise assessment, many studies have been carried out to estimate the day equivalent value, for which the actual noise level is approximated by one or a few short time measurements, for a duration that is much shorter than the full-day period, usually between minutes to a few hours [21-24]. An example of street categorization method shows that it is possible to estimate the day-time noise level by taking short time measurements which, depending on 
the category, could be improved by restricting the measurements to certain periods of the day [23]. Regarding the minimum time needed for a sample to be representative of a specific place, it has been found that measurements between 10 and 20 minutes are enough to represent the day value [23, 25]. Generally speaking, the criteria used to define the quality of the results is the time taken for the sound pressure to stabilize, e.g., that its fluctuation range be within a certain error interval, which is known as stabilization time $[26]$.

40 In this way, the year equivalent value can be estimated with a certain level of precision using noise levels from a number of days corresponding to a time period much shorter than a whole year. For annual $L_{D E N}$ estimation, researchers have shown that sampling random days during the year gives better precision and representativeness of year equivalent levels than

45 other techniques such as sampling consecutive days, only workdays or only weekends, or random full weeks [27]. Moreover, several authors use random sampling as a basis for comparison of optimizations or improvements proposed in sampling techniques for long-term level estimation [28-31].

The main objective of this study is to determine a sampling strategy which minimizes the estimation error and, consequently, allows for the estimation of the annual value with a reduced temporal sampling. A procedure involving temporal stratification could be used to reduce variability. It is possible to identify days within a week with lower variability that can be used to estimate unsampled days and lead to a better annual estimation. This study computes the average difference between weekend and workday equivalent noise levels, $L^{W d}-L^{W e}$, and uses it to estimate the weekend levels from the 
measurement of randomly selected workdays.

The research is structured as follows: section 2 presents information related to sampling points and measurement analysis; section 3 presents the proposed methodology; section 4 presents the weekday analysis that led to the proposed formula and the results of its application to different day periods and parameters; section 5 presents a discussion of the results and the temporal stratification strategy application for different day periods; and finally, section 6 presents the conclusions.

\section{Data}

Barcelona is the capital of Catalonia, which is one of the 17 autonomous communities of Spain. It is an important hub for services and tourism, with a land area of around $102.2 \mathrm{~km}^{2}$ and a population of about 1.6 million people according to the municipal register of inhabitants. It is the centre of a conurbation of about 3 million inhabitants. In summer, the climate is humid and hot, with temperature ranging between $23^{\circ} \mathrm{C}$ and $30^{\circ} \mathrm{C}$, while in winter it ranges between $9{ }^{\circ} \mathrm{C}$ and $12^{\circ} \mathrm{C}$. Average annual rainfall is approximately $600 \mathrm{~mm}$, with autumn being the most rainy season of the year.

A total of 14 Type 1 CESVA and 01dB sound level meters, equipped with an outdoor protection kit, were placed in 14 different streets in the city of Barcelona, at an equivalent height of around one storey (approximately $4 \mathrm{~m}$ above the ground according to the European Noise Directive). Measurements of $L_{\text {Aeq }}$ were continuously taken between 2010 and 2015. The measurement equipment was calibrated every year to ensure proper operation and accurate 
was originally set at between 1 second and 10 minutes for different sound meters. In the end, this study only used the data of one full year for each street. The chosen year for each street was the one with the fewest missing measurements.

Streets were categorized according to three different categories in which urban traffic is considered to be the main source of noise $[32,33]$ :

- Category 1: Urban ring roads or access roads. Roads that surround the city or that allow access to the city.

- Category 2: Main streets. Roads within the city which mainly distribute traffic throughout the urban area.

- Category 3: Ordinary streets. Mainly destination streets which are commonly used for residential, commercial or leisure purposes.

The locations of the measurements points are shown in Figure 1. According to previous experience $[23,33,34]$, higher traffic flow means more stable values and the categorization is stablished according to traffic flow order. The number of streets was also selected according this previous knowledge in order to get representative results. For category 1, less points were selected and measurement points were located in places where it is known to exist constant traffic flow. For category 2 and 3, the number of points was increased and they were located in streets with different traffic conditions and different use of the territory in order to verify that the proposed strategy was applicable in a more general way, i.e. not to be limited to certain types of streets or cities. Categories and supplementary information about each measurement point can be found in Table 1 . 


\begin{tabular}{cclccc}
\hline Point No. & Category & Street & Lanes & Parking & Year \\
\hline $\mathbf{1}$ & 2 & Passeig de Fabra i Puig & 3 & 1 & 2012 \\
$\mathbf{2}$ & 1 & Carretera de Collblanc & 4 & - & 2014 \\
$\mathbf{3}$ & 3 & Carrer dels Almogàvers & 4 & 1 & 2014 \\
$\mathbf{4}$ & 3 & Carrer de Villarroel & 4 & 2 & 2011 \\
$\mathbf{5}$ & 2 & Carrer de la Marina & 6 & - & 2011 \\
$\boldsymbol{6}$ & 2 & Av. del Paral-lel & 9 & 2 & 2012 \\
$\boldsymbol{7}$ & 3 & Carrer de Servet & 2 & - & 2011 \\
$\boldsymbol{8}$ & 2 & Rambla de Prim & 8 & 4 & 2013 \\
$\boldsymbol{9}$ & 3 & Carrer de Lincoln & 2 & 1 & 2014 \\
$\mathbf{1 0}$ & 3 & Carrer de Tuset & 3 & 2 & 2014 \\
$\mathbf{1 1}$ & 2 & Carrer de Balmes & 4 & - & 2010 \\
$\mathbf{1 2}$ & 3 & Carrer de Joan Güell & 3 & 1 & 2010 \\
$\mathbf{1 3}$ & 3 & Carrer de Sant Quintí & 4 & 2 & 2011 \\
$\mathbf{1 4}$ & 1 & Carrer de Beethoven (Side of Diagonal) & 3 & 1 & 2013 \\
\hline
\end{tabular}

Table 1: Supplementary information regarding the measurement points. Data regarding total number of lanes and how many of them are specifically designated for parking is shown. It also shows the measurement year chosen from the total sampled years (2010-2015). 


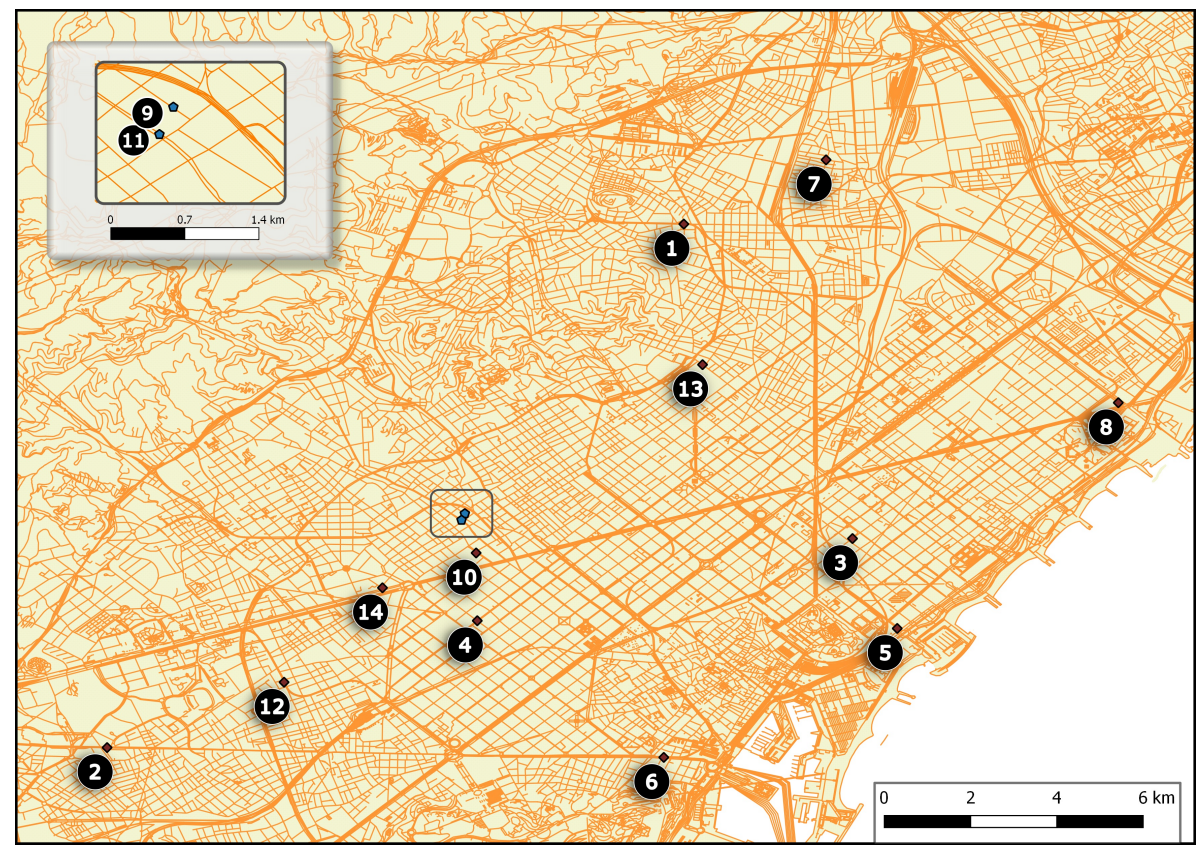

Figure 1: Location of the 14 measurement points.

$$
L_{D E N}=10 \log \left\{\frac{1}{24} \times\left(12 \times 10^{\frac{L_{\text {day }}}{10}}+4 \times 10^{\frac{L_{\text {evening }}+5}{10}}+8 \times 10^{\frac{L_{\text {nigh }}+10}{10}}\right)\right\}
$$

For each street, noise levels were analyzed in order to find any anomaly that could alter the actual year value [35]. For all the data presented in this

\section{Methodology}

The values in dBA of $L_{D E N}$ and $L_{d a y}$ (from 7 a.m. to 7 p.m.), $L_{\text {evening }}$ (from 7 p.m. to 11 p.m.) and $L_{\text {night }}$ (from 11 p.m. to 7 a.m.) for every single day and the actual annual level in each measurement point were calculated and stored in a local database. As described in [7], $L_{D E N}$ is calculated using the following equation: 
paper, a total of 14 days had $L_{D E N}$ values larger than $\left\langle L_{D E N}>+4 \sigma\right.$. These 14 values were considered abnormal and elimi-

115

nated. Furthermore, $70 \%$ of these eliminated days had values of $L_{D E N}$ larger than $\left\langle L_{D E N}>+6 \sigma\right.$. 9 of the eliminated days were especially noisy local celebrations (Sant Joan, la Mercè and a Champions League celebration). The reason for the high levels of the other 5 days eliminated could not be found.

\subsection{Statistical data calculation}

120 on temporal stratification. The methodology proposed is compared to the random days sampling strategy $[27,36]$.

Then, for each measurement point $i, 1,000$ samples of $N$ measurement days are taken according to each sampling strategy. The difference in dBA 125 between the equivalent level of each sample and the actual value is computed as:

$$
\Delta L_{j}^{i, N}=L_{p}^{i, N}(j)-<L_{p}^{i}>
$$

where $<L_{p}^{i}>$ is the actual annual value computed using all the days of the year for measurement point $i$ and period $p$. Where $p$ is day, evening, night or $D E N . L_{p}^{i, N}(j)$ is the level for period $p$ and measurement point $i$ computed 130

from the sample of $N$ days. $j$ is the current sample and runs from 1 to 1,000.

The number of sampling days $N$ runs from 1 to 28 .

The parameter used to perform the comparison between the proposed strategy and the random sampling strategy is the number of days that have to be measured in order to have $90 \%$ of the 1,000 samples inside the interval ${ }_{135}<L_{p}^{i}> \pm 1 d B$. In specific cases where 28 days is not enough to reach the 
desired percentage, $\mathrm{N}$ was increased until an appropriate number of days was reached.

Therefore, to compute the percentage of samples for $N$ days, the first step is to obtain the noise data which is stored in a local database. This connection provides a whole year of data for point $\mathrm{i}$ and for the required period $p$. $<L_{p}^{i}>$ is then computed to be used in Equation 2. After this, $L_{p}^{i, N}(j)$ is computed according to each sampling strategy and $\Delta L_{j}^{i, N}$ is calculated for $1 \leq j \leq 1,000$ and stored in the array

$$
\overrightarrow{L_{p}^{i, N}}=\left\{\Delta L_{1}^{i, N}, \Delta L_{2}^{i, N}, \ldots, \Delta L_{1000}^{i, N}\right\}
$$

Then, within the array, the percentage of samples inside $\left\langle L_{p}^{i}> \pm 1 d B\right.$ is obtained. Afterwards, the next measurement point data is selected from the data base and the whole process is repeated until all measurement points $(i=14)$ and $p$ periods are evaluated.

\subsection{Temporal stratification}

Apart from the physical characteristics of the street, noise depends on the types of noise sources, which could be due to traffic or other activities [34]. As this paper is focused only on traffic noise, the temporal noise evolution in each street depends mainly on the type and number of vehicles circulating through them, since physical street characteristics such as type of paving, obstacles and geometry usually never change within a street. For the purpose of this study, a temporal categoriation is proposed, differentiating working days from weekends. The temporal sampling for annual value estimation is limited to only workdays and the weekend level is calculated based on the 
workday/weekend difference. The following equation is proposed to estimate the weekend equivalent level in $\mathrm{dBA}$ as:

$$
L_{p}^{W e}=L_{p}^{W d}+<L_{p}^{W e-d}>
$$

160 workday and weekend noise levels of the place under study for period $p$ and $L_{p}^{W d}$ is the workdays equivalent value for the same period computed according to:

$$
L_{p}^{W d}=10 \log \left\{\frac{1}{N} \sum_{k=1}^{N} 10^{\frac{L_{p}(k)}{10}}\right\}
$$

where $N$ is the total number of sampled days and $L_{p}(k)$ is the day level for 165 period $p$ in $\mathrm{dBA}$.

Within a year [5/7] of the days are weekdays, $L^{W d}$, and $[2 / 7]$ are weekends, $L^{W e}$. Based on Equation 1 and changing parameters to adapt it to the aforementioned two temporal strata, the following equation is proposed to estimate the annual level in $\mathrm{dBA}$ for period $p$ based on $N$ working days chosen at random:

$$
L_{p}^{i, N}(j)=10 \log \left\{\frac{1}{7}\left(5 \times 10^{\frac{L_{p}^{W d}}{10}}+2 \times 10^{\frac{L_{p}^{W e}}{10}}\right)\right\}
$$

Then, estimating $L_{p}^{W e}$ from measurements taken during weekdays with Equation 4, the proposed temporal stratification strategy computes $L_{p}^{i, N}(j)$ as:

$$
L_{p}^{i, N}(j)=10 \log \left\{\frac{1}{7}\left(5 \times 10^{\frac{L_{p}^{W d}}{10}}+2 \times 10^{\frac{L_{p}^{W d}+<L_{p}^{W e-d}>}{10}}\right)\right\}
$$


For the case of the random sampling strategy, the following formulation 175 is applied to calculate $L_{p}^{i, N}(j)$ :

$$
L_{p}^{i, N}(j)=10 \log \left\{\frac{1}{N} \sum_{j=1}^{N} 10^{\frac{L_{p}(j)}{10}}\right\}
$$

\section{Results}

As stated in [31, 37, 38], differences between workdays and weekends can be found when studying the variability of days of the week. In the city under study, the working days are from Monday to Friday and the weekend days correspond to Saturday and Sunday.

Figure 2 shows the differences between the equivalent level computed only for workdays $L_{p}^{W d}$ and only for weekends $L_{p}^{W e}$, with the actual level $<L_{p}^{i}>$ as well as the levels $L_{p}^{W d}$ with $L_{p}^{W e}$ for all periods $p$. As one can see, $L_{p}^{W d}>L_{p}^{W e}$ except for some specific cases in the night period (Figure 185 $<L_{p}^{i}>$ with the day period being the one with the highest workday/weekend differences $\left\langle L_{p}^{W e-d}>\right.$. This seems to indicate stratification within the week that would allow $<L_{p}^{W e-d}>$ to be calculated for the estimation of weekend levels.

Figure 3 shows $L_{p}^{W d}$ and $L_{p}^{W e}$ levels for all periods and their $68 \%$ confidence interval for each of the measurement points with the aim of observing the overlapping of the confidence intervals. Workdays always show less variation than weekend days. Furthermore, for the day period, it is seen that the overlapping between workday and weekend confidence intervals is close 
(a)

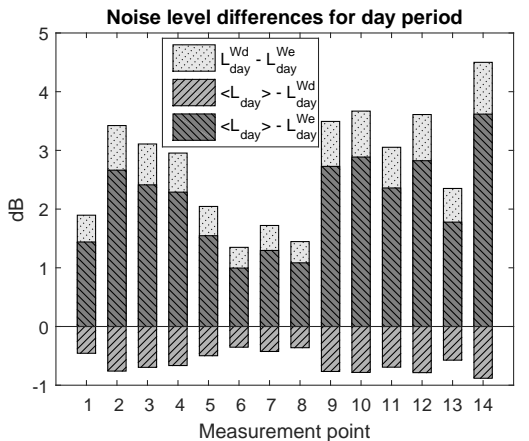

(c)

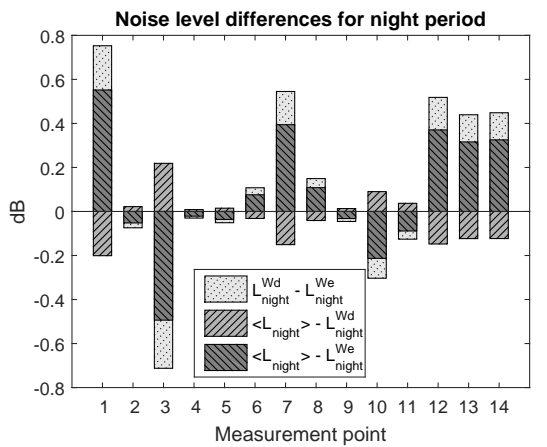

(b)

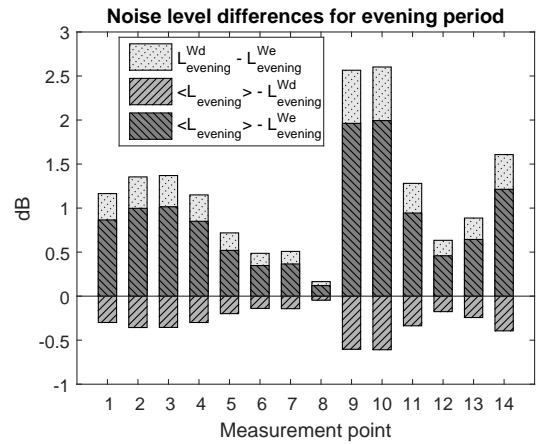

(d)

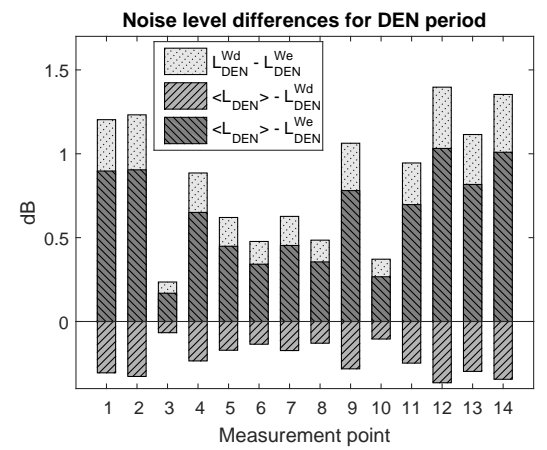

Figure 2: Difference between $\left\langle L_{p}>, L_{p}^{W d}\right.$ and $L_{p}^{W e}$ for all the periods and measurement points. 
(a)

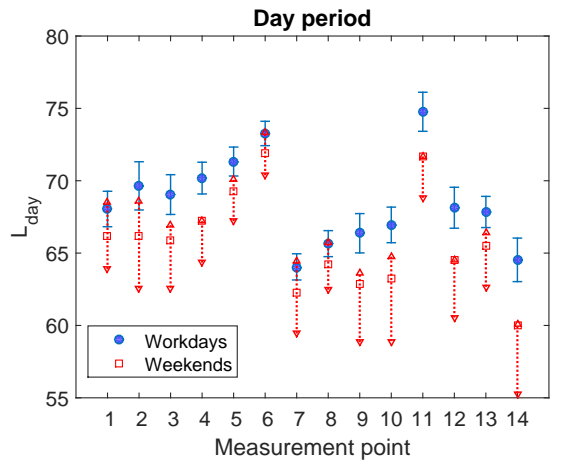

(c)

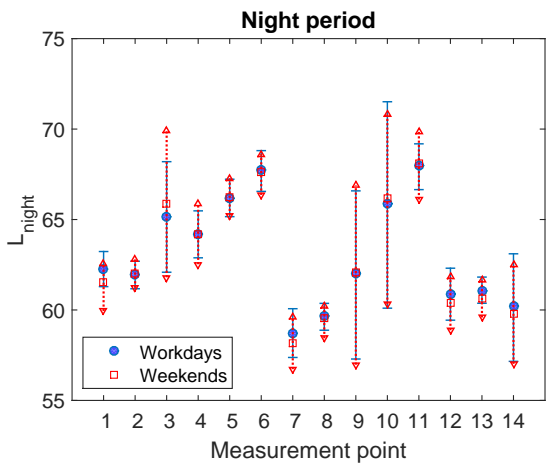

(b)

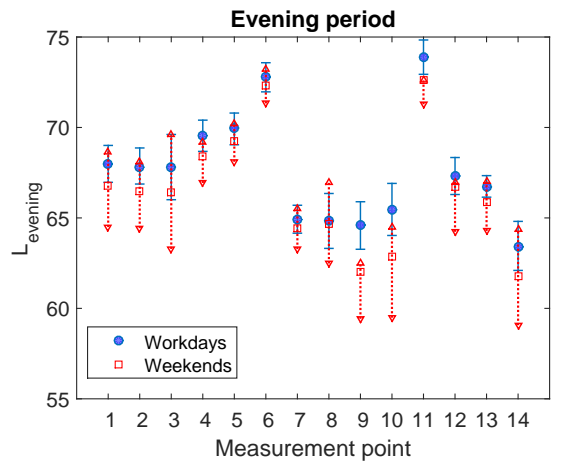

(d)

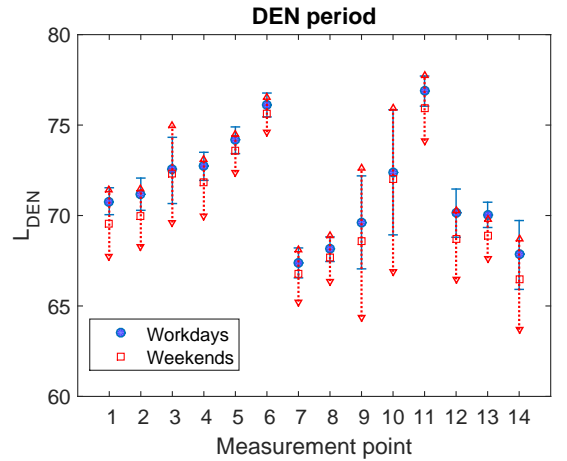

Figure 3: $L_{p}^{W d}$ and $L_{p}^{W e}$ mean and $68 \%$ confidence interval.

the other periods. In order to estimate $L_{p}^{W e}$ from $L_{p}^{W d}$, both quantities must come from populations with different means. Since according to a Chi-square goodness-of-fit test not all the distributions can be considered as normal, a non-parametric test should be used. The Wilcoxon rank-sum test was applied to both $L_{p}^{W d}$ and $L_{p}^{W e}$ to test the null hypothesis that both of them come from distributions with equal means. The result of this test is shown in Table 2. It can be seen that for $L_{d a y}$, workdays and weekends belong to different distributions; for $L_{\text {evening }}$ and $L_{D E N}$, mean independence is not achieved in only one of the measurement points; and for $L_{\text {night }}$, only four of the measurement points present distributions mean independence.

Thus, given the independence between $L_{p}^{W d}$ and $L_{p}^{W e}$ and the smaller 


\begin{tabular}{c|c|c|c|c|} 
Point & $L_{\text {day }}$ & $L_{\text {eve }}$ & $L_{\text {night }}$ & $L_{\text {den }}$ \\
\hline 1 & $9 E^{-18}$ & $3 E^{-13}$ & $4 E^{-11}$ & $2 E^{-17}$ \\
\hline 2 & $8 E^{-35}$ & $1 E^{-17}$ & 0.745 & $2 E^{-21}$ \\
\hline 3 & $7 E^{-41}$ & $8 E^{-13}$ & 0.075 & 0.132 \\
\hline 4 & $4 E^{-39}$ & $2 E^{-21}$ & 0.141 & $2 E^{-10}$ \\
\hline 5 & $3 E^{-35}$ & $1 E^{-10}$ & 0.864 & $2 E^{-10}$ \\
\hline 6 & $1 E^{-10}$ & $8 E^{-04}$ & 0.977 & $3 E^{-03}$ \\
\hline 7 & $4 E^{-25}$ & $8 E^{-07}$ & $7 E^{-03}$ & $9 E^{-09}$ \\
\hline 8 & $4 E^{-21}$ & 0.079 & $1 E^{-03}$ & $5 E^{-10}$ \\
\hline 9 & $3 E^{-37}$ & $3 E^{-31}$ & 0.965 & $2 E^{-05}$ \\
\hline 10 & $2 E^{-35}$ & $8 E^{-25}$ & 0.562 & $4 E^{-02}$ \\
\hline 11 & $1 E^{-11}$ & $2 E^{-06}$ & 0.982 & $2 E^{-04}$ \\
\hline 12 & $1 E^{-17}$ & $1 E^{-07}$ & 0.076 & $4 E^{-08}$ \\
\hline 13 & $6 E^{-25}$ & $6 E^{-16}$ & $5 E^{-06}$ & $1 E^{-20}$ \\
\hline 14 & $5 E^{-20}$ & $6 E^{-09}$ & 0.559 & $2 E^{-04}$ \\
\hline
\end{tabular}

Table 2: Test for distribution mean independence. Grey box indicates rejection that the data sets come from the same distribution $(\mathrm{p}=5 \%)$. The $p$ value is shown inside each cell.

variability of $L_{p}^{W d}$, it is possible to establish a temporal stratification that separates workdays and weekends. However, this would not reduce the size of the sample unless the weekend values are estimated from workday levels [34]. ${ }_{210}$ Estimating the weekend level by setting $\left\langle L_{p}^{W e-d}>\right.$ as close as possible to the actual difference for each point would bring a very accurate approximation of the actual weekend level; this should be better in cases where $\left\langle L_{p}^{W e-d}\right\rangle$ is higher, since $L_{p}^{W e}$ estimation takes greater importance when its value is much smaller than $L_{p}^{W d}$ as it is related to a higher distribution mean separation. Nevertheless, the noise level difference between workdays and weekends $<L_{p}^{W e-d}>$ should be known for each of the sampling points, which is not always possible. The calculation of $\left\langle L_{p}^{W e-d}>\right.$ requires the accurate measurement of $L_{p}^{W e}$ and $L_{p}^{W d}$ from a large sample of days. Therefore, if one had the actual values of $L_{p}^{W e}$ and $L_{p}^{W d}$ it would not be necessary to estimate 
${ }_{220}<L_{p}^{W e-d}>$.

4.1. Annual $L_{p}$ estimation by using $<L_{p}^{W e-d}>$ as computed average

Since previous noise data for each sampling point is not always available for noise assessment of a city, the overall average for all measurement points and the average by category is used as the $\left\langle L_{p}^{W e-d}>\right.$ parameter.

Then, $<L_{p}^{W e-d}>$ was first calculated for each measurement point using the following formula obtained from Equation 4:

$$
<L_{p}^{W e-d}>=L_{p}^{W e}-L_{p}^{W d}
$$

Table 3 shows the values of $\left\langle L_{p}^{W e-d}\right\rangle$ for each $p$ period computed individually for street categories and for all the streets.

The required number of days to have $90 \%$ of $\Delta L_{p}^{i, N}$ within $\pm 1 \mathrm{~dB}$ are shown in Table 4 for both strategies and for all periods.

\section{Discussion}

Even though there is a reduction in the required number of days in most of the cases presented in Table 4, there are some specific measurement points where the random sampling strategy is not improved or equalled.

For $L_{d a y}$, it is observed that, in almost all of the measurement points there is a reduction in the required number of days using Equation 7 compared to using the random sampling strategy. The total reduction in days sampled by applying the temporal stratification strategy compared to random sampling strategy is more than $38 \%$ using $\left\langle L_{d a y}^{W e-d}>\right.$ from the overall 240 average and more than $39 \%$ using $\left\langle L_{\text {day }}^{W e-d}>\right.$ from the category average. 


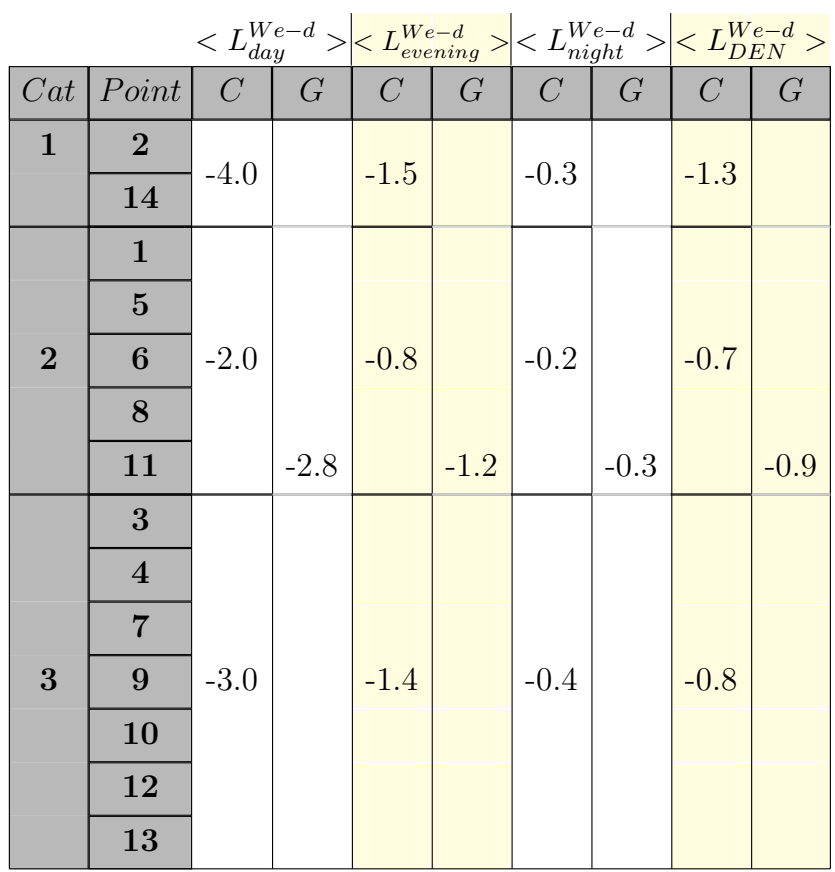

Table 3: $\left\langle L_{p}^{W e-d}>\right.$ computed for each category $(C)$ and overall for all the streets $(G)$ for all periods. 


\begin{tabular}{|c|c|c|c|c|c|c|c|c|c|c|c|c|c|}
\multicolumn{2}{|c}{} & \multicolumn{3}{|c|}{$L_{\text {day }}$} & \multicolumn{3}{|c}{$L_{\text {evening }}$} & \multicolumn{3}{c|}{$L_{\text {night }}$} & \multicolumn{3}{|c|}{$L_{D E N}$} \\
\hline Point & $\mathbf{C a t}$ & $D_{R}$ & $D_{G}$ & $D_{C}$ & $D_{R}$ & $D_{G}$ & $D_{C}$ & $D_{R}$ & $D_{G}$ & $D_{C}$ & $D_{R}$ & $D_{G}$ & $D_{C}$ \\
\hline $\mathbf{1}$ & $\mathbf{2}$ & 7 & 6 & 5 & 7 & 6 & 6 & 10 & 8 & 9 & 4 & 3 & 3 \\
\hline $\mathbf{2}$ & $\mathbf{1}$ & 10 & 5 & 5 & 5 & 4 & 4 & 2 & 2 & 2 & 4 & 3 & 3 \\
\hline $\mathbf{3}$ & $\mathbf{3}$ & 9 & 6 & 6 & 19 & 16 & 15 & 23 & $\mathbf{3 0}$ & $\mathbf{3 0}$ & 12 & 12 & 11 \\
\hline $\mathbf{4}$ & $\mathbf{3}$ & 6 & 3 & 3 & 4 & 3 & 3 & 6 & 5 & 5 & 4 & 3 & 3 \\
\hline $\mathbf{5}$ & $\mathbf{2}$ & 4 & 3 & 3 & 3 & 3 & 3 & 4 & 4 & 4 & 3 & 3 & 2 \\
\hline $\mathbf{6}$ & $\mathbf{2}$ & 3 & 3 & 2 & 2 & $\mathbf{3}$ & 2 & 5 & 4 & 4 & 3 & 2 & 2 \\
\hline $\mathbf{7}$ & $\mathbf{3}$ & 8 & 5 & 5 & 4 & 4 & 4 & 7 & 7 & $\mathbf{8}$ & 5 & 4 & 4 \\
\hline $\mathbf{8}$ & $\mathbf{2}$ & 6 & 5 & 4 & 13 & $\mathbf{1 8}$ & $\mathbf{1 4}$ & 5 & 4 & 4 & 4 & 3 & 3 \\
\hline $\mathbf{9}$ & $\mathbf{3}$ & 12 & 7 & 7 & 9 & 6 & 7 & 48 & $\mathbf{5 1}$ & 48 & 25 & 21 & 23 \\
\hline $\mathbf{1 0}$ & $\mathbf{3}$ & 16 & 10 & 11 & 11 & 9 & 10 & 39 & $\mathbf{4 2}$ & $\mathbf{4 4}$ & 27 & $\mathbf{2 8}$ & 24 \\
\hline $\mathbf{1 1}$ & $\mathbf{2}$ & 7 & 3 & 4 & 4 & 3 & 3 & 7 & 6 & 5 & 4 & 3 & 2 \\
\hline $\mathbf{1 2}$ & $\mathbf{3}$ & 11 & 6 & 6 & 17 & 10 & 10 & 10 & 9 & 8 & 8 & 6 & 7 \\
\hline $\mathbf{1 3}$ & $\mathbf{3}$ & 7 & 4 & 5 & 4 & 3 & 3 & 3 & 2 & 2 & 3 & 2 & 2 \\
\hline $\mathbf{1 4}$ & $\mathbf{1}$ & 13 & 7 & 6 & 10 & 6 & 6 & 23 & $\mathbf{2 4}$ & 22 & 13 & 11 & 12 \\
\hline Total & & $\mathbf{1 1 9}$ & $\mathbf{7 3}$ & $\mathbf{7 2}$ & $\mathbf{1 1 2}$ & $\mathbf{9 4}$ & $\mathbf{9 0}$ & $\mathbf{1 9 2}$ & $\mathbf{1 9 8}$ & $\mathbf{1 9 5}$ & $\mathbf{1 1 9}$ & $\mathbf{1 0 4}$ & $\mathbf{1 0 1}$ \\
\hline
\end{tabular}

Table 4: Number of days required to make the $90 \%$ confidence interval of $\left\langle L_{p}^{i}> \pm 1 d B\right.$ for the random sampling strategy $\left(D_{R}\right)$ and temporal stratification strategy, computing $<L_{p}^{W e-d}>$ as the measurement point average $\left(D_{G}\right)$ and category average $\left(D_{C}\right)$ for all periods. Measurement points are shown in bold italics where there is an increase in the required number of days with respect to the random sampling strategy. 
For measurement point 6, as shown in Figures 2 and 3, the combination of the low variability, which requires fewer days to reach the desired confidence interval, and the fact that $\left\langle L_{d a y}^{W e-d}>\right.$ by category is closer to the actual value, leads to a reduction in the required days when using the value per category and not with the overall average.

For $L_{\text {evening, }}$, in all but two streets, the random sampling estimation is equalled or improved with an average reduction in the required days by more than $16 \%$ and $19 \%$ by computing $\left\langle L_{\text {evening }}^{W e-d}>\right.$ as the overall or category average, respectively. The low variability of measurement point 6 is reflected 250 $<L_{\text {evening }}^{W e-d}>$ as the overall average is more than double the value compared to the individual one, makes the overall average less suitable for this measurement point than the category one. For measurement point 8, there are several reasons that could lead to the increase in the number of required days. that does not meet the distribution mean independence which, combined with its high variability, causes the estimation of $L_{p}^{W e}$ using the temporal stratification strategy to be inaccurate.

For the night period, in all but four measurement points, the random sampling estimation is equalled or improved. As seen in the total number of days for this period, there is no overall reduction; however, if we look at the measurement points individually, the increase in the number of days is concentrated in only four of the whole set of measurement points: 3, 9, 10 and 14. For the particular case of measurement point 3, 28 days are not 265 enough using both, overall or category average as $\left\langle L_{\text {night }}^{W e-d}>\right.$. This lack 
of improvement may be associated with the combination of high variability, the fact that $L_{n i g h t}^{W d}$ and $L_{n i g h t}^{W e}$ come from the same distribution and that the condition $L_{\text {night }}^{W d}>L_{\text {night }}^{W e}$ is not fulfilled. This is also observed in points 9, 10 and 14. It can be seen that, for the night period, some specific measurement points do not give as good results as for other periods. In order to establish the reason for this, a revision of the surrounding area was performed.

For measurement point 14, which is one of the main ring roads of Barcelona and also a commercial hub of the city, it was found that the possible reason for $L_{n i g h t}$ to be higher at weekends could be due to its extensive link with 275 commercial areas, as the road is full of large shopping centres, high-fashion clothing and jewellery stores, and some night clubs which could increase traffic flow on non-working days.

For measurement points 3 and 9, it was observed that their location is in the same street as well-known nightclubs. This means that their proximity to the clubs could increase the traffic flow during early and late night periods, as well as noise due to human interactions.

Measurement point 7 is located in front of a park on a narrow street with vehicle circulation mainly from the people living in the neighbourhood. Something to emphasize for this point is that, even though the test for distribution mean independence indicated means separation and that it meets the condition $L_{n i g h t}^{W d}>L_{n i g h t}^{W e}$, a reduction in the number of required days was not achieved. The possible reason for obtaining this result could be that $<L_{\text {night }}^{W e-d}>\approx 0.6 d B$, which for the overall and category average is even lower $(<0.5 \mathrm{~dB})$. This small value is a negligible difference and makes the temporal stratification strategy unsuitable for this point. 
Measurement point 10 is located in a narrow street in which there is a high concentration of commercial areas and restaurants. At approximately 150 metres from the measurement point there are two small-sized night clubs which could greatly affect the traffic flow, as there is only one lane for circulation.

It is observed that almost all of the aforementioned measurement points are affected by leisure activity. This activity implies that the variability of the $L_{p}^{W e}$ levels is very high (as seen in Figure 3) which, combined with the fact that $L_{p}^{W e}$ and $L_{p}^{W d}$ come from the same distributions, means that the estimation based on $L^{W d}$ is not a suitable strategy for these measurement points.

Finally, for $L_{D E N}$, a similar result as the day period is obtained. It is seen that, by using $\left\langle L_{D E N}^{W e-d}>\right.$ as the category average, the required number of days is reduced for every measurement point. When using the overall average there is a reduction in the required days in all but one measurement point.

If the proposed strategy were to be used in different cities, the parameters to be adapted to each place under assessment are $<L_{p}^{W e-d}>$ and the number of working days and weekend days, which for Barcelona are 5 (from Monday to Friday) and 2 (Saturday and Sunday), respectively. The selection of an accurate $\left\langle L_{p}^{W e-d}>\right.$ value is essential to obtain significant improvements. In terms of noise data, if there is enough previous information available, $<L_{p}^{W e-d}>$ could be computed as the category average and, in cases where there is little information available, an overall average could be used. As shown in Table 4, for the temporal stratification strategy, results are better when using $<L_{p}^{W e-d}>$ for each street category, as the required number of 
days is reduced even further compared to $\left\langle L_{p}^{W e-d}>\right.$ obtained as an overall average for all streets. As shown in this research, a combination of the proposed methodology together with the street categorization method is a very good option; this would help to save resources and increase the estimation accuracy as it would only require as many $\left\langle L_{p}^{W e-d}>\right.$ values as street categories under study. As noise pollution is becoming a priority issue in cities, the number of fixed networks is growing [39-44]. This means that the $<L_{p}^{W e-d}>$ could easily be obtained for a larger number of measurement points, which would increase the accuracy of the temporal stratification strategy.

\section{Conclusion}

It has been shown that, in the city of Barcelona, there is a temporal stratification for days of the week as their values follow different distributions, with the workday noise level being higher and the variability being lower than for weekends. Based on this temporal stratification, a new sampling strategy was introduced. It was shown that measuring only on workdays and estimating weekend noise level from the $\left\langle L_{p}^{W e-d}>\right.$ value, brings a significant improvement in accuracy compared to the random sampling strategy for the estimation of the annual $<L_{p}^{i}>$. For the case of the annual $<L_{D E N}^{i}>$

335 estimation, using $\left\langle L_{D E N}^{W e-d}\right\rangle$ by category led to an improvement for each of the sampling points studied, for which the average reduction is 1.29 days per measurement point compared to the random sampling strategy.

The temporal stratification strategy works well for streets with normal traffic, but in those with significant leisure activity, a high variability is de- 
340

tected for night period values, which leads to poorer results than the random sampling strategy, for the aforementioned reasons. The proposed method assumes that $<L_{p}^{W d}>\neq<L_{p}^{W e}>$; if this is not true, as it is in most of the cases for the night period, the temporal stratification strategy does not bring a significant improvement as $\left\langle L_{p}^{W e-d}\right\rangle \approx 0$. This means that, at this time, it is advisable to apply the temporal stratification strategy to streets where traffic is due to regular people displacement, and for the streets with a strong presence of leisure activities, further research is required as the performance is not so good because of the local effect of these activities on the surrounding traffic. All this suggests that it is necessary to carry out double categorization: one by type of street and the other by use of the area.

For the entity in charge of the noise assessment of a city, using the categorization method together with the proposed strategy, makes the sampling process less demanding as the measurements only have to be done on working days and in a reduced number of sampling points. Furthermore, the improvements in accuracy lead to a reduction in the number of sampling days required to equal or improve the population coverage with respect to using the random sampling strategy. The proposed methodology, allows the authorities in charge of environmental management to get traffic noise data faster and saving resources without compromising the precision and representativeness of the noise levels.

\section{Acknowledgements}

The authors would like to thank Barcelona City Council for providing the noise data used in this study. This work is part of the doctoral thesis 
by Guillermo Quintero that is under way at the Polytechnic University of

Catalonia (UPC) with grant support provided by CONACyT.

\section{References}

[1] S. A. Stansfeld, M. P. Matheson, Noise pollution: Non-auditory effects on health, British Medical Bulletin 68 (2003) 243-257. doi:10.1093/bmb/ldg033.

[2] L. Sobotova, J. Jurkovicova, Z. Stefanikova, L. Sevcikova, L. Aghova, Community response to environmental noise and the impact on cardiovascular risk score, Science of the Total Environment 408 (6) (2010) 1264-1270. doi:10.1016/j.scitotenv.2009.12.033.

[3] M. Basner, W. Babisch, A. Davis, M. Brink, C. Clark, S. Janssen, S. Stansfeld, Auditory and non-auditory effects of noise on health, The Lancet 383 (9925) (2014) 1325-1332. arXiv:NIHMS150003, doi:10.1016/S0140-6736(13)61613-X.

[4] J. C. Blanco, I. Flindell, Property prices in urban areas affected by road traffic noise, Applied Acoustics 72 (4) (2011) 133-141. doi:10.1016/j.apacoust.2010.11.004.

[5] W. H. Organization, Health as the Pulse of the New Urban Agenda, in: United Nations Conference on Housing and Sustainable Urban Development, October 2016.

[6] E. A. King, H. J. Rice, The development of a practical framework for 
strategic noise mapping, Applied Acoustics 70 (8) (2009) 1116-1127. doi:10.1016/j.apacoust.2009.01.005.

[7] Diario Oficial de las Comunidades Europeas, Directiva 2002/49/CE del Parlamento Europeo y del Consejo de 25 de junio de 2002 sobre evaluación y gestión del ruido ambiental, Ministerio de la Presidencia de España (2002) 25.

[8] D. W. Morley, J. Gulliver, Methods to improve traffic flow and noise exposure estimation on minor roads, Environmental Pollution 216 (2016) 746-754. doi:10.1016/j.envpol.2016.06.042.

[9] E. A. King, E. Murphy, H. J. Rice, Implementation of the EU environmental noise directive: Lessons from the first phase of strategic noise mapping and action planning in Ireland, Journal of Environmental Management 92 (3) (2011) 756-764. doi:10.1016/j.jenvman.2010.10.034.

[10] M. Hamed, W. Effat, A gis-based approach for the screening assessment of noise and vibration impacts from transit projects, Journal of Environmental Management 84 (3) (2007) 305-313.

[11] Advances in the development of common noise assessment methods in Europe: The CNOSSOS-EU framework for strategic environmental noise mapping, Science of the Total Environment 482-483 (1) (2014) 400-410. doi:10.1016/j.scitotenv.2014.02.031.

405

[12] S. Givargis, H. Karimi, A basic neural traffic noise prediction model for Tehran's roads, Journal of Environmental Management 91 (12) (2010) 2529-2534. doi:10.1016/j.jenvman.2010.07.011. 
[13] D. W. Morley, K. De Hoogh, D. Fecht, F. Fabbri, M. Bell, P. S. Goodman, P. Elliott, S. Hodgson, A. Hansell, J. Gulliver, International scale implementation of the CNOSSOS-EU road traffic noise prediction model for epidemiological studies, Environmental Pollution 206 (2015) 332341. doi:10.1016/j.envpol.2015.07.031.

[14] P. Cohen, O. Potchter, I. Schnell, The impact of an urban park on air pollution and noise levels in the Mediterranean city of Tel-Aviv, Israel., Environmental pollution (Barking, Essex : 1987) 195 (2014) 7383. doi:10.1016/j.envpol.2014.08.015.

[15] L. Maffei, M. Masullo, Electric vehicles and urban noise control policies, Archives of Acoustics 39 (3) (2014) 333-341. doi:10.2478/aoa-2014-0038.

[16] Y. Avsar, B. D. Gumus, The application of noise maps for traffic noise reduction, Noise Control Engineering Journal 59 (6) (2011) 715-723. doi:doi:10.3397/1.3650259.

[17] J. Romeu Garbí, S. Jiménez Diaz, G. F. Meritxell, S. V. Ángel, Recreation noise in acoustic mapping, no. 43, Internoise, Lisbon, Portugal, 2010, pp. 1-10. doi:10.13140/RG.2.1.4473.6409.

[18] E. M. Salomons, S. A. Janssen, H. L. Verhagen, Local impact assessment of urban traffic noise, Noise Control Engineering Journal 62 (6) (2014) 449-466. doi:doi:10.3397/1/376242.

[19] F. Zuo, Y. Li, S. Johnson, J. Johnson, S. Varughese, R. Copes, F. Liu, H. J. Wu, R. Hou, H. Chen, Temporal and spatial variability of traffic- 
related noise in the City of Toronto, Canada, Science of the Total Environment 472 (2014) 1100-1107. doi:10.1016/j.scitotenv.2013.11.138.

[20] J. M. Barrigón Morillas, C. Ortiz-Caraballo, C. Prieto Gajardo, The temporal structure of pollution levels in developed cities, Science of the Total Environment 517 (2015) 31-37.

[21] H. Safeer, J. Wesler, E. Rickley, Errors due to sampling in community noise level distributions, Journal of Sound and Vibration 24 (3) (1972) $365-376$.

[22] C. H. Ng, S. K. Tang, On monitoring community noise using arbitrarily chosen measurement periods, Applied Acoustics 69 (7) (2008) 649-661. doi:10.1016/j.apacoust.2007.01.003.

[23] J. Romeu, M. Genescà, T. Pàmies, S. Jiménez, Street categorization for the estimation of day levels using short-term measurements, Applied Acoustics 72 (8) (2011) 569-577. doi:10.1016/j.apacoust.2010.09.012.

[24] C. Prieto Gajardo, J. M. Barrigón Morillas, Stabilisation patterns of hourly urban sound levels, Environmental monitoring and assessment 187 (1) (2015) 4072. doi:10.1007/s10661-014-4072-3.

[25] L. Brocolini, C. Lavandier, M. Quoy, C. Ribeiro, Measurements of acoustic environments for urban soundscapes: choice of homogeneous periods, optimization of durations, and selection of indicators., The Journal of the Acoustical Society of America 134 (1) (2013) 813-821. doi:10.1121/1.4807809. 
[26] A. J. Torija, D. P. Ruiz, Á. Ramos-Ridao, Required stabilization time, short-term variability and impulsiveness of the sound pressure level to characterize the temporal composition of urban soundscapes, Applied Acoustics 72 (2-3) (2011) 89-99. doi:10.1016/j.apacoust.2010.09.011.

[27] E. Gaja, A. Gimenez, S. Sancho, A. Reig, Sampling techniques for the estimation of the annual equivalent noise level under urban traffic conditions, Applied Acoustics 64 (1) (2003) 43-53.

[28] R. Makarewicz, M. Galuszka, Empirical revision of noise mapping, Applied Acoustics $72 \quad$ (8) (2011) 578-581. doi:10.1016/j.apacoust.2010.10.012.

[29] C. Prieto Gajardo, J. M. Barrigón Morillas, G. Rey Gozalo, R. VílchezGómez, Can weekly noise levels of urban road traffic, as predominant noise source, estimate annual ones?, The Journal of the Acoustical Society of America 140 (5) (2016) 3702-3709. doi:10.1121/1.4966678.

[30] A. Can, T. Van Renterghem, M. Rademaker, S. Dauwe, P. Thomas, B. De Baets, D. Botteldooren, Sampling approaches to predict urban street noise levels using fixed and temporary microphones., Journal of Environmental Monitoring 13 (10) (2011) 2710-9. doi:10.1039/c1em10292c.

[31] M. Hueso, A. Giménez, S. Sancho, E. Gaja, Measurement techniques of noise level in various urban scenarios. Day selection and representative period, Applied Acoustics 116 (2017) 216-228. doi:10.1016/j.apacoust.2016.09.033. 
[32] J. M. B. Morillas, V. G. Escobar, J. A. M. Sierra, R. Vílchez-Gómez, J. M. Vaquero, J. T. Carmona, A categorization method applied to the study of urban road traffic noise, The Journal of the Acoustical Society of America 117 (5) (2005) 2844-2852. doi:10.1121/1.1889437.

[33] S. Jiménez, M. Genescà, J. Romeu, A. Sánchez, Estimation of night traffic noise levels, Acta Acustica united with Acustica 94 (4) (2008) 563-567. doi:10.3813/AAA.918065.

[34] J. Romeu, S. Jiménez, M. Genescà, T. Pàmies, R. Capdevila, Spatial sampling for night levels estimation in urban environments., The Journal of the Acoustical Society of America 120 (2) (2006) 791-800.

[35] C. P. Gajardo, J. M. B. Morillas, V. G. Escobar, R. Vílchez-Gómez, G. R. Gozalo, Effects of singular noisy events on long-term environmental noise measurements, Polish Journal of Environmental Studies 23 (6) (2014) 2007-2017.

[36] J. M. Barrigón Morillas, C. Prieto Gajardo, Uncertainty evaluation of continuous noise sampling, Applied Acoustics 75 (1) (2014) 27-36. doi:10.1016/j.apacoust.2013.07.005.

[37] P. Mioduszewski, J. A. Ejsmont, J. Grabowski, D. Karpiński, Noise map validation by continuous noise monitoring, Applied Acoustics 72 (8) (2011) 582-589. doi:10.1016/j.apacoust.2011.01.012.

[38] R. Khaiwal, T. Singh, J. P. Tripathy, S. Mor, S. Munjal, B. Patro, N. Panda, Assessment of noise pollution in and around a sensitive zone 
in North India and its non-auditory impacts, Science of the Total Environment 566-567 (2016) 981-987. doi:10.1016/j.scitotenv.2016.05.070.

[39] V. Bruno, F. Fradet, P. Sylvain, The Development of a Permanent Network for Measuring Environmental Noise at the Urban-Area Level, acoucité (2).

[40] D. Geraghty, P. Mcdonald, I. Humphreys, Analysis of Urban Noise in Dublin Using Long-Term Data From a Publically Accessible Permanent Monitoring Network, in: ransportation Research Board 94th Annual Meeting, Vol. 15-3943, 2015.

[41] D. I. Mihajlov, M. R. Prascevic, Permanent and Semi-permanent Road Traffic Noise Monitoring in the City of Nis (Serbia), Low Frequency Noise, Vibration and Active Control 34 (3) (2015) 251-268. doi:10.1260/0263-0923.34.3.251.

[42] K. Vogiatzis, Environmental noise and air pollution monitoring in the athens ring road (attiki odos') an important parameter for a sustainable urban development, International Journal of Sustainable Development and Planning 10 (4) (2015) 528-543. doi:10.2495/SDP-V10-N4-528-543.

[43] A. Czyzewski, J. Kotus, M. Szczodrak, Online urban acoustic noise mon515 itoring system, Noise Control Engineering Journal 60 (1) (2012) 69-84, cited By 4. doi:10.3397/1.3670102.

[44] Dublin City Council, Dublin City Council Annual Report and Accounts 2010, Tech. rep. (2011). 